\title{
Evaluation of Water Amount in Hydrated Ethanol Fuel by Gamma-ray Attenuation Technique
}

\author{
José M. de Oliveira Jr. ${ }^{\text {a }}$ Ítalo C. O. Silva ${ }^{\mathrm{a}}$, Bruno R. Malaquias ${ }^{\mathrm{a}}$ and \\ Antonio C. G. Martins ${ }^{\mathrm{b}}$ \\ ${ }^{a}$ Universidade de Sorocaba - UNISO, Cidade Universitária, Caixa Postal 578, \\ Rod. Raposo Tavares, Km 92.5, 18023-000, Sorocaba, SP, Brazil \\ ${ }^{b}$ Universidade Estadual Paulista Julio de Mesquita Filho - UNESP, GASI, \\ Av. 3 de Março, 511, Alto da Boa Vista, 18087-180, Sorocaba, SP, Brazil
}

\begin{abstract}
In this work, is presented an alternative and non conventional technique for evaluate the water amount present in the hydrated ethanol used as automotive fuel. The standard technique used in this kind of measure is the use of densimeter. The proposal of this work is based on the measure of the linear attenuation coefficient of hydrated ethanol, using the gammaray attenuation technique. The water amount, in volume, can be determined knowing the linear attenuation coefficient of hydrated ethanol. Samples of hydrated ethanol, collected at fuel stations, located in Sorocaba, SP, Brazil, were analyzed and the results showed the feasibility of the technique.
\end{abstract}

Keywords: Attenuation of Gamma-rays, Hydrated Ethyl Alcohol, Ethanol, Fuel, Density. PACS: $81.70 . \mathrm{Tx} ; 82.80 . \mathrm{Ej} ; 29.25 . \mathrm{Rm} ; 29.30 . \mathrm{Kv}$

\section{INTRODUCTION}

Since the discovery of phenomenon of natural radioactivity by $\mathrm{H}$. Becquerel in 1896, began emerging ideas of applications of this new science. One of the first experimental studies describing the use of ionizing radiation was developed by Belcher et al. [1] in the 50's. In subsequent years, new applications began to emerge in various fields of science: studies to determine the density of material made of cement base [2], determining the density of soil [3], etc.. In this work, we suggest the use of gamma-ray attenuation technique, to determine the percentage of water present in hydrated ethanol used as automotive fuel. We analyzed a series of samples of ethanol, collected at fuel stations that sell this fuel, randomly selected and located in city of Sorocaba, SP, Brazil.

\section{MATERIALS AND METHODS}

The methodology used here is based on gamma-ray attenuation. This fact is described by the attenuation law, proposed by Lambert-Beer [4]. Consider a beam of mono-energetic gamma-rays, focusing on a material of thickness $\mathrm{x}$ and density $\rho$. The

XXXIII Brazilian Workshop on Nuclear Physics

AIP Conf. Proc. 1351, 275-279 (2011); doi: 10.1063/1.3608971

(C) 2011 American Institute of Physics 978-0-7354-0908-8/\$30.00 
intensity I (cps) of the emerging beam is related to the intensity I0 (cps) of the incident beam by the Lambert-Beer law, i.e.:

$$
I=I_{0} e^{-\mu^{*} \rho x},
$$

where $\mathrm{x}(\mathrm{cm})$ is the total thickness, $\rho\left(\mathrm{g} / \mathrm{cm}^{3}\right)$ the density and $\mu^{*}\left(\mathrm{~cm}^{2} / \mathrm{g}\right)$ the mass attenuation coefficient of absorbing material, respectively. The intensities are given in number of photons per unit of time. The mass attenuation coefficient $\mu^{*}\left(\mathrm{~cm}^{2} / \mathrm{g}\right)$, is related to the linear attenuation coefficient $\mu\left(\mathrm{cm}^{-1}\right)$, through the relation $\mu=\mu^{*} \rho$.

Ferraz and Mansell [5] proposed that the mass attenuation coefficient for a heterogeneous material is directly related to the chemical composition of the material, i.e., the theoretical mass attenuation coefficient can be assumed to be the sum of the products of mass attenuation coefficients, of each chemical element composing the material, multiplied by its respective percentage in the sample, i.e.:

$$
\mu^{*}=\sum_{i=1}^{n}\left(R_{i} \mu_{i}^{*}\right)=R_{1} \mu_{1}^{*}+R_{2} \mu_{2}^{*}+\ldots \ldots \ldots+R_{n} \mu_{n}^{*},
$$

where $\mathrm{i}$ is the number that identifies the chemical element present in the sample, $\mathrm{R}_{\mathrm{i}}$ is the percentage of the ith chemical element present in the sample and $\mu_{\mathrm{i}}{ }^{*}$ is the mass attenuation coefficient of the ith element. Whereas samples of hydrated ethanol fuel are made of ethanol and water, we can write:

$$
\mu^{*}=\mu_{\text {alc. }}^{*} R_{\text {alc. }}+\mu_{\text {ag. }}^{*} R_{\text {ag. }},
$$

being $\mu^{*}$ álc. and $\mu^{*}$ ág. the mass attenuation coefficients of alcohol and water respectively and $R_{\text {álc. }}$ and $R_{\text {ág. }}$ the ratios between the volumes of alcohol and water in relation to the total volume, respectively. Quantities $\mathrm{R}_{\text {álc. }}$ and $\mathrm{R}_{\text {ág. Were defined as: }}$

$$
R_{\text {alc. }}=\frac{V_{\text {alc. }}}{V_{t}}=\frac{X_{\text {alc. }}}{X_{t}} \quad \text { and } \quad R_{\text {ág. }}=\frac{V_{\text {ag. }}}{V_{t}}=\frac{X_{\text {ag. }}}{X_{t}}
$$

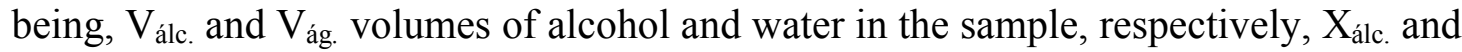
$X_{\text {ág. }}$ the equivalent thickness of water and alcohol, with $V_{t}=V_{\text {alc. }}+V_{\text {ág. }}$ and $X_{t}=X_{\text {ác. }}+X_{\text {ág. }}$ the volume and the total thickness of the sample, respectively.

Substituting the definitions given in Equation (4) in Equation (3), using the relationship between the mass attenuation coefficient $\mu^{*}$ and the linear attenuation coefficient $\mu\left(\mu^{*}=\mu / \rho\right)$, defining the sample density $\rho=\left(\rho_{\text {álc. }} V_{\text {álc. }}+\rho_{\text {ág. }} V_{\text {ág. }}\right) / V_{t}$, by a weighted average, having as weights in the average, the volume of each substance and considering the relationships $\mathrm{R}_{\text {ág. }}=\mathrm{X}_{\mathrm{a} g} / \mathrm{X}_{\mathrm{t}}$ and 1- $\mathrm{R}_{\mathrm{ág}}=\mathrm{X}_{\mathrm{álc}} / \mathrm{X}_{\mathrm{t}}$, we obtain Equation (5), which provides the theoretical function between the quantity of water present in hydrated ethanol fuel and the linear attenuation coefficient, i.e.:

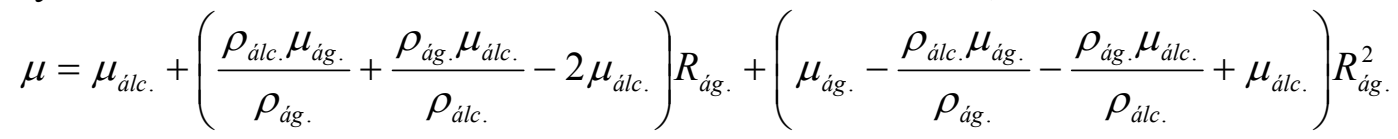

Equation (5) shows a quadratic dependence between the amount of water Rág. and the linear attenuation coefficient $\mu$ of the sample. Knowing this coefficient and the coefficients of water and ethanol, and their densities, one can determine the amount of water present in the sample. The experimental set-up, makes use of an Americium-241 gamma-ray source $\left(\mathrm{E}=59,6 \mathrm{keV}\right.$ and $3,7 \times 10^{9} \mathrm{~Bq}$ of activity), a $\mathrm{NaI}(\mathrm{Tl})$ scintillation detector coupled a standard electronic for signal processing. The system was calibrated using samples of pure water and ethyl alcohol $\left(\mathrm{CH}_{3} \mathrm{CH}_{2} \mathrm{OH}\right)$. Measurements were 
made to obtain the linear attenuation coefficient of ethyl alcohol and water. For purposes of calibration, was also measured the linear attenuation coefficient of ethyl alcohol diluted in water in different concentrations. The linear attenuation coefficient of water and ethanol was also determined theoretically, using the XCOM program [6]. The results were used to test the theoretical model represented by Equation (5). The value of the quantity of water obtained by gamma-ray attenuation methodology was compared with the results obtained using the traditional methodology, i.e., via measurement of density.

\section{RESULTS AND DISCUSSION}

Using the XCOM program was determined the mass attenuation coefficients of water and ethyl alcohol. After multiplying these coefficients by their densities $\left(\rho_{\text {water }}=1 \mathrm{~g} / \mathrm{cm}^{3}\right.$ e $\left.\rho_{\text {alcohol }}=0.7876 \mathrm{~g} / \mathrm{cm}^{3}\right)$, we obtained the theoretical linear attenuation coefficient for water $\left(0.2070 \mathrm{~cm}^{-1}\right)$ and for alcohol $\left(0.1583 \mathrm{~cm}^{-1}\right)$. The linear attenuation coefficients were also obtained experimentally from the Equation (1). The experimental values obtained for the linear attenuation coefficient of water and alcohol were $\mu_{\text {ág. }}=(0.2000 \pm 0.0006) \mathrm{cm}^{-1}$ e $\mu_{\text {álc. }}=(0.1560 \pm 0.0005) \mathrm{cm}^{-1}$, respectively. Replacing the theoretical values in Equation (5), we obtain the theoretical relationship between the amount of water and linear attenuation coefficient, i.e.:

$$
\mu=0.15830+0.04742 R_{\text {ág. }}-0.00128 R_{\text {ag }}^{2} .
$$

The solid line in Fig. 1 represents the graph of Equation (6) and the dotted line is the best fit to experimental data, when a quadratic function is used $\left(\mu=0.015763+0.05944 \mathrm{R}_{\text {ág. }}-0.01345 \mathrm{R}_{\text {ág. }}^{2}\right.$, with correlation coefficient equal to $\left.\mathrm{r}^{2}=0.9972\right)$.

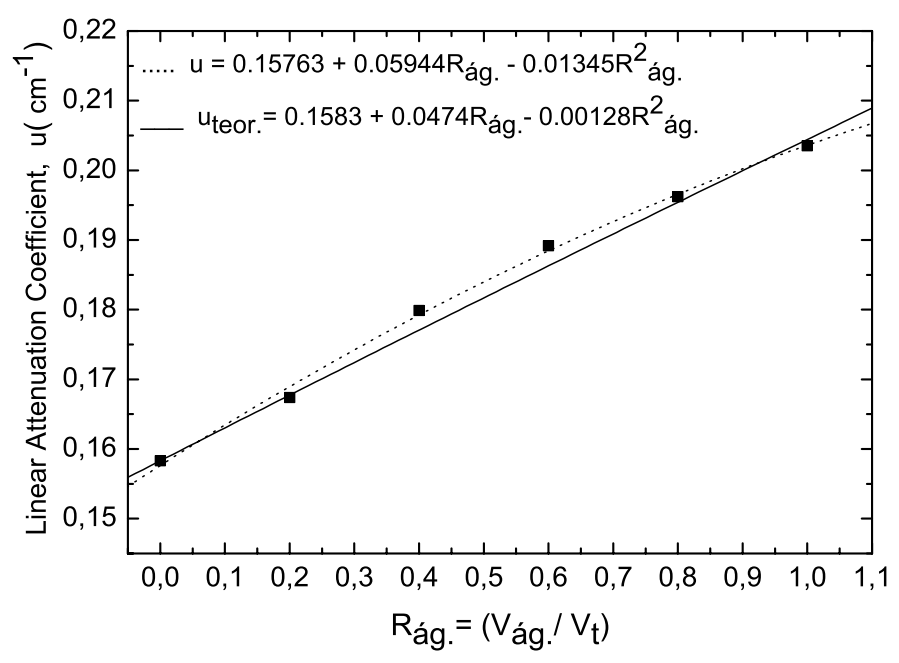

FIGURE 1. Graph shows the dependence of the linear attenuation coefficient versus the water amount. The solid line is the graph of Equation (6), while the dotted line represents the quadratic curve that best fits the experimental data.

Table 1 shows the results of the samples analyzed in this study. 
TABLE 1. Values of linear attenuation coefficient $\mu$ and water amount $\mathrm{R}_{\text {ág.. }}$ present in hydrated ethanol fuel samples. The number followed by a letter, identifies the fuel station. The acronym CB is used for fuel stations who work with flag and symbol SB for those working without a flag. $\mathrm{R}^{\text {Teor. }}{ }_{\text {ag. }}(\%)$ is the result obtained by use of Equation (6) and $\mathrm{R}^{\text {Exp. }}$ ág. $(\%)$ is the best fit to experimental data.

\begin{tabular}{|c|c|c|c|}
\hline Fuel station & $\mu\left(\mathrm{cm}^{-1}\right)$ & $\mathbf{R}^{\text {Teor. }}{ }_{\text {ág. }}(\%)$ & $\mathrm{R}_{\text {ág. }}^{\text {Exp. }} \%$ \\
\hline 1-SB & $0.1620 \pm 0.0005$ & $7.82 \pm 0.12$ & $7.48 \pm 0.15$ \\
\hline 2-CB & $0.1623 \pm 0.0005$ & $8.53 \pm 0.13$ & $8.06 \pm 0.16$ \\
\hline 3-SB & $0.1618 \pm 0.0005$ & $7.41 \pm 0.11$ & $7.14 \pm 0.14$ \\
\hline 4-CB & $0.1610 \pm 0.0005$ & $5.89 \pm 0.09$ & $5.89 \pm 0.11$ \\
\hline 5-CB & $0.1614 \pm 0.0005$ & $6.69 \pm 0.10$ & $6.55 \pm 0.13$ \\
\hline 6-SB & $0.1643 \pm 0.0005$ & $12.89 \pm 0.19$ & $11.69 \pm 0.23$ \\
\hline 7-SB & $0.1646 \pm 0.0005$ & $13.36 \pm 0.20$ & $12.07 \pm 0.24$ \\
\hline
\end{tabular}

The National Agency of Petroleum, Natural Gas and Biofuels of Brazil (ANP), determine in its Technical Regulation $\mathrm{N}^{0} 7 / 2005$ (2005) [7], that the water volume allowed for hydrated ethanol, have to be between $6.2 \%$ and $74 \%$. Fig. 2 shows the values $\mathrm{R}^{\text {Teor. }}$ ág. $(\%)$ and $\mathrm{R}^{\text {Exp. }}$ ág. $(\%)$, along with the limits imposed by the ANP, while Fig. 3, shows the amount of water obtained by traditional method, i.e., by measuring the density of the samples, together with data obtained by gamma-ray attenuation.

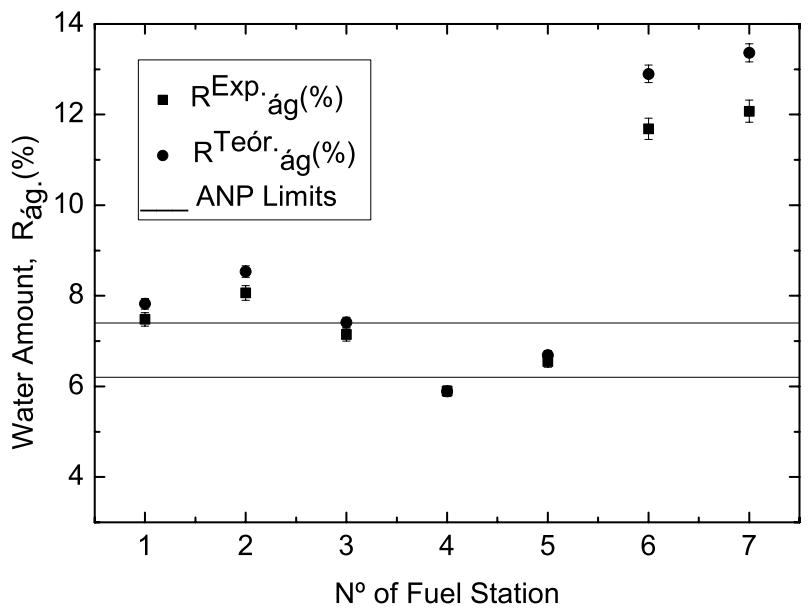

FIGURE 2. Graph shows the values of amount of water, in percentage, measured using gamma-ray methodology, being that the squares and spheres represent the experimental and theoretical value for $\mathrm{R}_{\mathrm{a} g}$. The solid horizontal lines indicate the limits set by ANP. 


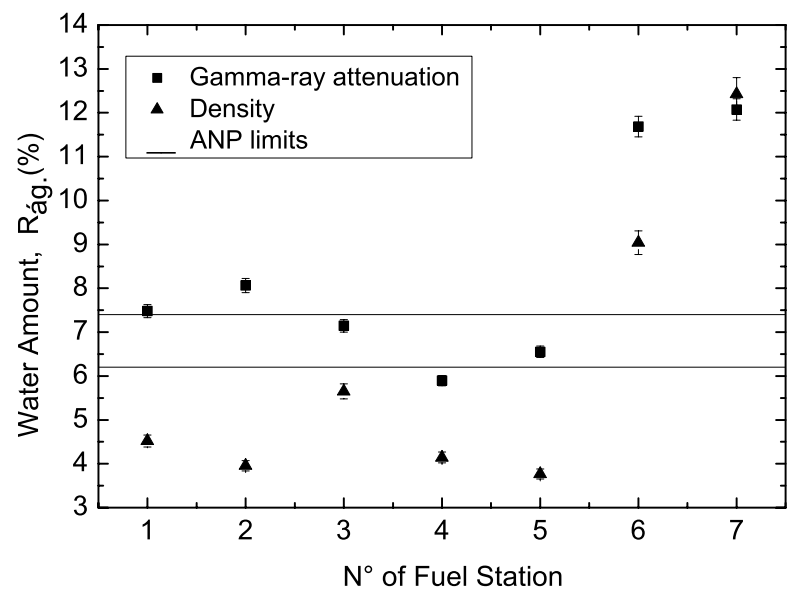

FIGURE 3. Graph shows the amount of water obtained by traditional method, i.e., by measuring the density of the samples, together with data obtained by gamma-ray attenuation. The solid horizontal lines indicate the limits set by ANP. Squares are data obtained via gamma-ray attenuation and triangles come from traditional methodology.

\section{FINAL CONSIDERATIONS}

We analyzed the amount of water present in samples of hydrated ethanol used as automotive fuel. The method employed to analyze the amount of water, was an unconventional technique, i.e., the gamma-ray attenuation and one traditional which is the measure of density. The two methodologies have different values for the amount of water, but not quite disparate, i.e., show the same general behavior. The samples that contained more water ( $\mathrm{N}^{\mathrm{o}} 6$ and 7 ), came from fuel station without a flag. The data presented here show that approximately $30 \%$ of the fuel stations, which sell hydrated ethanol in the city of Sorocaba, selling this fuel, adulterated, i.e., the ethanol have more water in volume than allowed by the ANP, and $100 \%$ these fuel stations are classified how without flag.

\section{REFERENCES}

1. D. J. Belcher, T. R. Cuykendall and H. S. Sack. Tech. Dev. Rep. 127, 1-20, Civ. Aeron. Admin., Tech. Dev. and Eval. Center, Washington, D. C. (1950).

2. E. E. Smith, and A. C. Whiffin. Density measurement of concrete slabs using gamma radiation. The Engineers, Publisher, London, 1952, pp. 278-281.

3. J. A. Vomocil. Soil Sci., 77, 341-342 (1954).

4. Siegbahn, K., Alpha, beta and gamma-Ray Spectroscopy, Publisher, North-Holland Company, Amsterdam, New York, Oxford, 1979, pp. 37-76.

5. Ferraz, E. S. B.; Mansell, R. S. University of Florida, Tech. Bulletin Nº 807 (1979).

6. Hubbel, J. H., Berger, M. J., X-COM: photon cross section on a personal computer. NBSIR 87-3597, US Department of Commerce, National Bureau of Standards, Gaithersburg, MD (1987).

7. Regulamento Técnico ANP No7/2005, (2005).

http://nxt.anp.gov.br/NXT/gateway.dll/leg/resolucoes anp/2005/dezembro/ranp\%2032-

$\% 202005 . x m l ? \mathrm{f}=$ templates $\$ \mathrm{fn}=$ default.htm\&sync=1\&vid=anp:10.1048/enu, accessed April 08, 2010. 
Copyright of AIP Conference Proceedings is the property of American Institute of Physics and its content may not be copied or emailed to multiple sites or posted to a listserv without the copyright holder's express written permission. However, users may print, download, or email articles for individual use. 